INTRODUCTION

\title{
Labour and Employment in a Globalising World
}

\author{
Christian AZAÏS ${ }^{1}$
}

Recent transformations in work and employment in developed countries may well be reproducing situations once typical of the developing world. Flexibility and corporate decision-making autonomy, recasting of workers' rights and trade union roles are now firmly embedded on public policy agendas. These challenges depend on the ability of social actors to impact labour markets and the scope of their influence. Labour and Employment in a Globalising World: Autonomy, collectives and political dilemmas is a collection of essays which explore topical issues regarding work and employment from South to North. The book contextualises South-North comparisons within globalisation and converging patterns as one of its component parts. The postulate poses globalisation as a force of both standardisation and differentiation. Institutional and negotiating models standardise as they accommodate autonomous work tendencies and legal grey zones. The forms they take differ with regards to national and historical particularities.

The South-North political paradigm is innovative and also engenders a paradox: growing disparities and irregularities within labour and employment markets tend, as well, to converge. This does not, however, preclude conflict, for the process of differentiation dominates the one of standardisation, both being characteristic traits of modern day capitalism. The paradigm is political as it impacts the workplace and beyond, society in the broad sense. It is a driving force of globalisation.

This introduction endeavours to illustrate how political globalisation contextualises labour and employment. It is a more realistic depiction than the reductionist economic construct. It then lays out the book's content and initiates a pluridisciplinary debate through the problematical approaches of the authors.

1 This introduction would not be what it is without the remarkable and sharp dedication and generosity of my friend and colleague Donna Kesselman. Let her be sincerely and deeply thanked for the rewriting job. Mariane Georgopoulos translated several articles from French to English. A great merci to her. 


\section{When Globalisation Sheds Light on Politics}

Globalisation is a comprehensive process of multi-level social, economic and political interdependencies. The "local", nonetheless, is of particular relevancy.

Globalisation is said to heighten market competition, as it punctuates the world's economies. Thus Suzanne Berger underscores "the changes in the international economy and in domestic economies that are moving toward creating one world market [...] To make this term [globalisation] a useful one, it needs to be pared down to the core idea, which is the emergence of a single world market for labour, capital, goods and services". And she continues: "a more concrete definition of globalisation, then, is the acceleration of the processes in the international economy and in domestic economies that operate toward unifying world markets" (Berger, 2006: 9). The definition is too static. For Saskia Sassen (2002), globalisation is the equivalent of hyper-mobility: international networks of communication and the elimination of problems inherent in distance and localisations. It's the spatial dimension which is emphasised here. Globalisation does transform the spatial and socioeconomic scales of regulation (Swyngedouw, 2000). But this movement does not contradict the local dimension as enterprises continue to depend upon territories and their human capital, they are not mere predators of lower labour costs. The quality of the labour force - its education standards, skills and adaptability -, institutional stability and reactivity are conditions of sustainable economic development.

Globalisation is political as it incites glocal interactions and interdependencies. It is neither a 'win-win' nor a 'win-lose' relationship, but impacts the way groups act, interact and assimilate ongoing transformations. Appropriate tools are needed to apprehend its repercussions upon work and employment in their respective national environments.

Globalisation is paradoxical precisely because these phenomena cannot be standardised. Its differentiations are as much contextual as they are analytical because they are perceived from multiple viewpoints. (Assayag, 2005). Global and local are not contradictory, the glocal is inherently comprehensive. The viewpoints are conditioned by the factors advanced to justify a particular problematical stance. For example, the ideology of neoliberal market regulation reduces all social processes to their economic component and relegates the other dimensions of capitalism - ecology, culture, politics, civil society - to "the sway of the world-market system", whose defining trait is what Ulrich Beck calls "globalism" (Beck, 2000b: 100). According to "globalism", an economy which engulfs all other single societal phenomena modifies one's perception of reality. When praising globalisation, neoliberal economists point to the expansion of world trade and take for granted Montes- 
quieu's statement: "trade smoothes mora". They subsequently call for opening up all borders towards inexorable world-market consolidation. Trade is viewed as the ultimate vehicle of world-wide wealth distribution. Whether economics is a justifiably dominant doctrine with regards to market interactions is not at issue here, but that one must not, as Beck reminds us, disregard the other dimensions of capitalism, notably politics, which neoliberal theory tends to take for granted.

Globalisation obliges the researcher to change her/his own naturally bilateral viewpoint as is cogently illustrated by Uzbek's premise, borrowed from Montesquieu's Les Lettres persanes, that globalisation is in essential conflict with ethnocentrism. When she studies the young Turkish population in Germany and their behaviour towards religion and dress codes, Valérie Amiraux concludes that they adopt a new "façon d'être" - self identity - which is just as valid as that of the kemalian period. Her starting point differs from typical Euro-centric thematics (Amiraux, 2002 in Giraud, 2007: 394). The same is true for Jackie Assayag when he examines globalisation and its impact upon India (Assayag, 2005). Both analyses emphasise distinct and interacting logics that cannot be reduced to the economy. They help to comprehend the various dimensions of globalisation, which are inexorably intertwined while not identical, once the thread of politics is pulled.

In this way, David Held et al. highlight the distinction between hyperglobalists, transformationalists and sceptics (Held et al., 1999: 10). The former conceive globalisation as the dawn of a new age (Ohmae, 1990), arising from the erosion of national-state potency. The nationstate is a thing of the past, bowing to technology and capitalism as the new driving force of the world market. Today's actuality of systemic crisis and the renewed assertion of sovereign authority reveals the flaws in this view.

Transformationalists argue that interconnectedness has reached heretofore unattained heights. The nation-state's power has declined. Globalisation is a transformative medium of state ascendancy and world politics and thus converges in both integration and fragmentation of intermediate spaces (Held et al., 2000).

By comparison sceptics point to the persistent prevalence of states and markets (Hirst, Thompson, 1999). They acknowledge and promote the dual movement of internationalisation and regionalisation, while disputing the claim that globalisation actually produces any radical change. National predominance and sovereignty prevail.

More recently, in his definition of globalisation, Olivier Giraud enhances the centrality of the nation-state, be it as the prerequisite vehicle for engendering any form of new world organisation or for grasping the meaningful consequences of its decline. In any case globalisation is a 
challenge the state and the nation must grapple with. As NonGovernmental Organisations (NGO), transnational actors, interrelations, Internet, mafias, etc., increasingly occupy the political sphere they broaden the scope of state jurisdiction and, to the least, concern. Thus, globalisation is complex for it remains the "central producer of politics" (Giraud, 2007), but not the only one: "Globalisation [...] denotes the processes through which sovereign national states are criss-crossed and undermined by transnational actors with varying prospects of power, orientations, identities and networks" (Beck, 2000b: 101).

Globalisation can also be discerned through interlocking characteristics at all levels - international, national or regional..., as Giraud observes: "Globalisation is a dynamic more counterposed to the national framework than bound to it" (Giraud, 2005: 113). This view highlights the role of the state as a conveyer of changing power relations, as illustrated by Held et al. (1999): "Sandwiched between global forces and local demands, national governments are having to reconsider their roles and functions". Then Giraud explains globalisation's three fundamental impacts: "First, it accentuates the transformative power dynamics of the main political actors in their national setting. It simultaneously bolsters the international diffusion of new ideas, schemes of interaction, frames of reference. Finally, it comforts emerging paradigms of political regulation which embody international collective action"2 (Giraud, 2005: 106107). The following contributions express the functioning of the "international diffusion of new ideas" and relevant political regulations with regards to work and employment.

Globalisation correlates at once to a "broadening, deepening and speeding up of world-wide interconnectedness in all aspects of life" (Held et al., 2000). This includes political life in nation-states, turning them into 'decision takers' instead of 'decision makers'. Therefore, globalisation does not simply reflect increasingly transnational economic and non-economic relations. It implies emerging types of structures and coexisting processes (Mayntz, 1998: 8).

Globalisation is also a "process (or set of processes) which embodies a transformation in the spatial organisation of social relations and transactions, generating transcontinental or interregional flows and networks of activity, interaction and power" (Held et al., 1999). According to

The Swiss case referred to by Giraud in this book illustrates this hypothesis. "En premier lieu, elle renvoie à la transformation des rapports de pouvoir des principaux acteurs intervenant au sein même des systèmes politiques nationaux. (...) la globalisation est également associée au renforcement de la diffusion internationale de nouvelles idées, modèles d'action, cadres de référence. (...) Enfin, la globalisation renvoie à une série de nouvelles régulations politiques qui sont l'expression d'une action collective internationale". 
Göran Therborn (2000: 154), globalisation illustrates "tendencies to a world-wide reach, impact, or connectedness of social phenomena or to a world-encompassing awareness among social actors". As the concept thus englobes several processes, Therborn proposes it be used in the plural: globalisations.

Defining globalisation as a 'universalising' phenomenon occasions the re-invention of differences (Assayag, 2005: 19-20). In fact, globalisation and the supposed modernity it triggers (Beck, 2000a; Serksnyte, below) are the complex result of multiple and previous interactions. Some of them are obvious; some are obscure or laying in wait. Thus, globalisation is a composite of contradictory processes which proceed in multiple directions and ways (Assayag, 2005: 271).

In this fabric of "increasing diversity" (Assayag, 2005), a multiplicity of problematic anchor points combine to apprehend globalisation as a single process of standardisation and differentiation, the approach adopted in this book. It entails as well a tendency to individuation: the individual is individual thanks to her/his dialogical relation to the group (Assayag, 2005: 295), thus expanding upon the economics-based, ideologically reductionist paradigms.

The field of work and employment globalisation impacts the way subjectivities and identities are re-calibrated; how they are part of us, of our certainties and expectations. It is simultaneously creative and destructive, expressed through "accommodations and adaptations, translations and appropriations, and even interbreeding and hybridisations" (Assayag, 2005: 276).

Thus, globalisation reinforces the glocal sphere, and herein lies the general statement of this book. Globalisation is at the core of the work and employment debate through its plethora of forms and contractual relations. They are inclined to converge in an overlapping space between developing and developed countries. As an economic, political and social phenomenon our analysis draws upon the relevant interdisciplinary literature, various national case studies and thematic perspectives. Its unity stems from the central function of politics in all these realms.

Our analysis of current trends structures globalisation's impact into three main themes, from macro to micro perspective, each advancing its particular conceptual blueprint. The first outlines what has changed in labour market policies; the second, in labour-management negotiations, the last is more work-centred; focusing upon autonomy at work and the evolutions of the capitalist workplace.

The articles concur in their critical stance towards neo-liberal acceptance of globalisation. Economic and social thought has primarily dealt with four major concerns: "the present form of world economy; the 
dominant regime of capitalist accumulation; the modes and effectiveness of contemporary economic governance; and the robustness of national economic autonomy and sovereignty" (Held McGrew, 2000: 19). These concerns are applied to work and employment in the articles here. The perspectives they propose from the South as from the North thus provide partial but contextualised visions from wide-ranging disciplinary angles.

This book is not a comparative work stricto sensu; term-to-term comparisons tend to compartmentalise social phenomena, with often ethnocentric overtones. Work and employment are the products of societal structuring and can rarely be removed from their original settings without the risk of distorting their substance. When international comparisons are carried out they most often remain embedded within their national labour markets. This partially explains the difficulties encountered in the formulation of European Union employment policies. ${ }^{3}$

The selected authors demonstrate how societies and cultures are impacted by the transformative dynamics of politics. Developing countries appear to be winning the cut-throat "race to the bottom" for lower wages and labour costs. Has globalisation thus altered the content of workers' exploitation? While these and other processes are of global scope, are not they structured by local constraints, such as labour force composition and labour-management institutions?

Globalisation enhances flexibilisation and casualisation in contemporary societies, ${ }^{4}$ but also differentiation among groups of workers. The concept of hybridisation introduces a spatial dimension which helps us grasp this phenomenon. Typical of post-industrial societies, it is closely linked to the emergence of new forms of work and widening wage scale differentials that result in individualisation. What used to be a characteristic of developing countries is ever more frequently encountered in developed ones. ${ }^{5}$ Hybridisation reflects the intertwining patterns of

3 The rejection of the European Constitutional Treaty by the French electorate in 2005 is basically due to its $3^{\text {rd }}$ part, dealing with social reforms and neo-liberal policies with regards to labour markets and welfare systems. The lack of political vision has also been attributed to referendum's defeat.

4 Gray uses the concept of "flexploitation" (Gray, 2004). However, "precarisation" was the term preferred in the call for the $11^{\text {th }}$ Biennial French International Sociology of Work Conference (JIST 2007 London): "Restructuring, precarisation and value".

5 In France, for instance, the steadiness of the wage distribution has changed in the last years. The wage per capita tends to increase, slowly but differently among workers. For example, during the $1998-2005$ period, the wage increase rate reached $1 \%$ for the P090-P100 deciles and $6.1 \%$ for the last $99^{\text {th }}$ one, which corresponds to a $50 \%$ variation during the period. The gap between the highest and the lowest wages has come to a peak, which strengthens the thesis of a globalisation sealed with differentiation and flexibilisation, i.e. the so-called hybridisation (Azaïs, Carleial, 2010). 
individual insertion in the labour market. It encompasses flexibilisation and casualisation and leaves its mark upon employment contracts. As a process, hybridisation illustrates how new work or contractual structures grow out of pre-existing forms and crystallize new categories of individual engagement. More than the simple combination of situations, hybridisation is a social "construction" in a globalising world and intervenes at various levels. It is a dynamic process of continuous adaptation, training and learning, which are proper to globalisation. It is also testimony to the fact that there can be no transposition of so-called models given the prevalence of societal and national conditions and their specificities. It signifies that transformations underway worldwide and encompassing entire economic sectors and territories generate reactions - local and global - and sustain the principle of differentiation as globalisation's core trend. In this sense, hybridisation depicts the diversity of situations workers are engaged in, and can be considered as one of its characteristic traits.

Several previously commonplace assumptions in Europe and other developed countries have since been called into question. One is the consensus around the pertinence of attempting to sustain a wage-earning society, founded upon the longstanding employment relationship, intimately linked to institutionalised social protection. This welfare state, which took years to reach maturity, has been subject to criticism in recent years. Despite predictions to the contrary, however, the welfare state has retained its function as the main social provider despite, as will be shown here, it's accommodation to the far-reaching effects of workfare. Several papers focus on this timely issue, mainly through the lens of activation policies.

This contrasts to the situation of countries in the South. First of all, the emergence of late capitalism (alternately christened as "underdeveloped" or "less developed" or even "developing") prevented labour markets from fully functioning as a social integrator, even when the wage-earning employment relationship had crystallised and become significantly generalised. This structuration, however, was unable to coalesce strong collective forces to protect vast numbers of workers. Mathias's expression "restricted wage-earning relation" (1987) renders such a relationship, as one which embodies a particular content. Consequently, at a time when the welfare state social contract is being brought into question in Northern countries, it is worth questioning whether a comparable process is underway in the South, and thus the applicability of this hypothesis in these countries.

The ubiquity of informal activities suggests that the status of work in countries of the South has not followed an identical trail as in the North. The comparison of these trajectories is a major contribution of our work. 
Furthermore, while we have chosen to adopt a simplified South/North distinction, each group of countries is composite so that no overall welfare state concept can apply. No all-encompassing definition can account for the multitude of experience, be it South or North. The contribution of this book and each of its articles highlights singular but converging features of globalisation in the labour market's various realms.

The book is divided into three parts. Each one focuses upon relevant national transformations in globalised labour markets. Can the South help us better apprehend impending transformative trends in the world of labour? To answer this question, the contributions shed light upon critical dimensions of globalisation through the lens of political review.

\section{Structure of the book}

Each part invites authors to comment upon timely issue related to work or employment. The contributors come from a variety of countries (Australia, Brazil, Finland, France, Germany and the USA) and academic backgrounds (Economics, Law, Philosophy, Political Science, Psychology and Sociology). Their fields of investigation include the countries mentioned above in addition to Denmark, Italy, Sweden and Switzerland, but not all contributions deal with a particular national case study. Some are more theoretical and transcend a single geographic or spatial sphere. The plurality of approaches is in itself a component of our hypothesis that globalisation is differentiated through its various analytical viewpoints.

Three main interrogations are raised respectively within each of the corresponding parts. The issues, though, are interrelated and differentially linked within a globalising labour market which has no strictly defined South-North border distinctions.

\section{Part 1}

The first part, entitled Legal frameworks: What has changed in labour market policies? investigates work and employment through institutional approaches to public policy, and more particularly activation policies. The three articles cover five countries - Brazil, Switzerland, Denmark, Finland and Sweden - in the complementary disciplines of economy, politics and law. Their broad-spectrum political approach is essential to understanding how local actors digest global employment trends and help reveal some of the differences they entail for countries be they South or North.

Starting with Brazil, Liana Maria da Frota Carleial, in her contribution, "The Brazilian Labour Market: Structural Features, 'New' Flexibilisation and Recent Performance", studies the constitution of this labour 
market. The historical overview insists upon how the adoption of a neoliberal agenda in the early 1990s resulted in fragmentation, deregulation and privatisation. These trends continued during President Lula's first administration when, during its first two years in power (2002-2004), the new left-wing government pursued essentially the same policies as the previous administration.

Carleial traces her argument from the early $20^{\text {th }}$ century to the $1990 \mathrm{~s}$, when Brazil introduced its neo-liberal agenda and flexibilisation became the overriding trait of the already casual Brazilian labour market. The labour market reforms introduced during the Cardoso administrations (1994-1997 and 1998-2001) were adopted without having to amend formally existing labour law. To do so, the former government used $a d-$ hoc congressional manoeuvres and the growing incidence of common law jurisprudence in favour of labour market flexibilisation. Under popular pressures for democracy neither President Cardoso nor his successor, President Lula, could initiate reforms without first working out consensus among the country's main institutional actors - employer associations, trade unions and, at times, Parliament. ${ }^{6}$ The central government thus played its traditional role of arbiter among conflicting social interests.

As for labour market trends in most developing countries, Brazil has been a social laboratory for the flexibility and casualisation which has now attained developed countries. For Carleial their root cause lies in what he terms the incomplete welfare state, thereby establishing a causal relationship with the degree of development.

When examining "The effects of activation measures on disadvantaged jobseekers' rights and obligations in Denmark, Finland and Sweden", Paul Van Aerschot spells out common features in activation policies, for training and other back-to-work programmes for jobseekers typify today's "shift from rights to obligations".

As they are essentially geared to opening labour markets such measures have uncertain results in terms of employment. For van Aerschot, a fine line exists between the sanctions imposed to enforce compulsory participation and the violation of a recipient's elementary worker rights. He proposes instead programmes designed to facilitate labour market entry for people with reduced employability through the creation or subsidising of specifically tailored jobs. Work-orientations should take into account the jobseeker's overall needs, which are not limited to employment and not treat them as mere clients. The approach exposes

6 Although President Cardoso's governments (1994-2001) frequently resorted to Medidas Provisórias (decree-laws adopted without the vote of the legislative branch). 
the gap between current practice and official public policy and provides an interpretation of globalisation in terms of contrasting cultural awareness. It also points to incipient modifications in the very nature of state institutions as in state theory.

Moreover, much as in the Brazilian case, tendencies towards more individualised treatment are manifest. This is to some extent due to employment agency preferences for more individual-centred missions, adapted to jobseeker's particular skills and abilities. For van Aerschot, these reforms have repercussions upon jobseekers' labour market positioning and the personal decisions she or he must take. The shift from a collective rights (or what the author calls "administrative-legal decisionmaking") to an individual-based approach violates previously existing rights to privacy and equal treatment. Indeed, individualised measures are not always suited to jobseekers' specific needs due to uncertainties derived from broad discretionary measures. Interactions between the jobseeker and frontline decision-maker matter, as does the role of intermediaries and the increased job-market flexibility the measures incur.

In this context, Switzerland is a specific case where federal law is rooted in precedents and enforced at both local (canton) and global/national, scales. In "Implementing the new Swiss employment policies in the context of globalisation" Olivier Giraud distinguishes between the good cantons, i.e., those implementing orthodox orientations, and the bad ones, which do not. The author examines the factors taken into account by cantons in the political choices they make and suggests that each canton enjoys some degree of leeway. The way each canton practically adapts federal employment decisions is a test-case of Swiss federalism and, at the meso level, of the main actors and political decision-makers in the employment arena. A specialist in cross-country studies, Giraud portrays executive federalism in Switzerland, especially the political determinants of transposing Federal Unemployment Insurance Law (LACI) to the canton level. This study depicts interactions between multi-level governance and generalised employment activation policies in Europe, the intricate relationship which articulates employment policy sanction and integration.

This book's first part opts for a macro analysis of labour policy and market structuration that conceives globalisation as a concrete construction. Each article presents, in its own way, the roadmaps countries adopt to navigate within an increasingly flexible world of work. Brazil, where work and employment flexibility have taken on substantial proportions, even for developing countries, is taken as a reference case. The main thesis is that labour market practices in a country like Brazil may be forerunners of mid- or longer term developments in developed coun- 
tries. In other words, can Southern countries be termed as large-scale "social laboratories" for metamorphoses underway? The authors have adopted several criteria to test this hypothesis, such as the impact of the change of scale in Switzerland: labour policies are primarily driven by the cantons with only minimal Federal intervention, thus punctuating the significance of the local.

Some elements of convergence emerge from the case studies. Neoliberal agendas are implemented in all countries, though more so in Brazil than in Switzerland, Denmark, Finland or Sweden, and all labour market policies have implemented some form of activation. The state is the key player. Citizens are termed as 'clients', forced to improve their own personal employability in order to obtain social benefits when applying for vocational training. The European Employment Strategy, as put forward by the OMC - Open Method of Co-ordination, includes various mediations opening to alternative processes and result in their uniformisation. This clearly shows that diverse mediations produce different arrangements and therefore that globalisation in employment matters does not obey a unique purpose (Zeitlin and Pochet, 2005).

What distinguishes the three contributions is the particular configuration of the role of the state. The Brazilian state can hardly be compared to its Danish, Finnish, Swiss equivalents, mainly due to their specific historical developments and positioning in international political, economic and social relations.

Methodologically, in their respective approach as to the Brazilian and the Scandinavian cases, the texts by Carleial and van Aerschot are macro-oriented, while Giraud combines macro and meso concerns at both federal and canton levels. He thus paves the way for Part 2. While employment policies are the centre of concern of the first part, the second marks a change of scale, towards the local state and firm levels in Brazil and France. Our focus in this part is labour and management relations. It sets the terms of the debate around today's workplace, which will be developed in the final part.

\section{Part 2}

Decentralisation and specialisation of labour and employer associations: emerging negotiation paradigms turns around two main issues: decentralisation and specialisation. One has a spatial dimension while the other, an organisational one. The contributions analyse the way negotiations take place at the micro level, since the adoption of new management principles by firms and, at macro and meso levels, through the implementation of France's recent industrial policy of "poles of competitiveness" (pôles de compétitivité). The difference of scale between labour-management interactions, on the one hand, and the 
mainly top-down governmental approach, on the other, elucidates the impact of state employment policies in a deregulating labour market.

The authors - a sociologist and an economist - outline the political challenges faced by both firms and governments. Paola Cappellin, "Entrepreneur associations and trade unions: towards a merging of the labour policy agenda?", spells out the new dilemma for firms, virtually compelled to integrate financial imperatives when establishing human resources policies. She borrows from Northern American literature when adapting the concept of 'social responsibility' to Brazilian business associations and organisations, and how they internalize these concerns. She then looks at corporate social practices in the state of Rio de Janeiro and how trade unions relate to corporate social responsibility (CSA). While a product of global market competition, the forms of social responsibility vary, especially according to the size of firms. She also portrays CSA as an expression of growing interdependency between corporate and social actors which neither party can afford to avoid. Cappellin situates her argument between employment and labour, thereby announcing the major concerns of part 3 which specifically deals with work issues.

Through his analysis of French industrial policy, Jacques Perrat's piece "Territorialised industrial policies and new spatial divisions of labour: what is at stake for socio-economic actors?", deals with labour market regulation and, in doing so, covers both spatial and organisational spheres. For Perrat there has been a shift from a functional division of labour, typical of the Fordist period, to a mix of horizontal differentiation of localised blocks of skills that have an impact on territorial rating. He is particularly preoccupied with the repercussions this has on workplace conditions. The author then looks at the alternative strategies adopted by trade unions to face these challenges.

Both Cappellin and Perrat emphasise the meso level and the growing interactions between firms and trade unions, just as the key role the latter are playing in the globalising labour market. Their articles bridge the gap between shopfloor and institutional considerations of the evolution of modern-day capitalism. They conclude with the observation that worker autonomy is among its major trends, which transitions us to the book's third and final part.

\section{Part 3}

Individual autonomy vs. collective responsibility in a flexible world of work takes on the issue in a strict sense, the core of labour issues studied here. Seven authors address concrete experiences of autonomy at work and place them in the broader context of contemporary capitalism. 
The reflexion opposes individual autonomy and collective responsibility and dwells upon the meaning of this autonomy in a flexible world of work. Concepts such as atomisation and controlled (or conceded) autonomy are explored. They are illustrated though themes such as "Autonomy at work", on the shopfloor and "Autonomy and capitalism" at more globalising labour market levels. Both offer insights into what is actually changing in the world labour market and how practices in the South are likely markers for future developments in the North. Nevertheless no generalisation can be definitively drawn from the sole example of Brazil.

The cases described in chapter "Autonomy at work", by two sociologists and two economists refer to the United States, France and Italy in the North, and to Brazil in the South. Related articles in the following chapter B, "Autonomy in capitalism", are more general, even if Germany is portrayed as a prominent reference case.

\section{Autonomy at work}

In his contribution, "Autonomy, general working capacity and collective action", Patrick Dieuaide explores the deeper meaning of "autonomy". The term is used indiscriminately to refer to what in fact are distinct phenomena: the "worker's own initiative" to act, autonomy defined by the hierarchy (what he calls "managerial injunction"), or the "professional autonomy" of the specialist who "owns" her/his own skills and know-how. In this sense, Dieuaide's piece introduces the discussion pursued by Cinara Rosenfield. Both agree that the polysemy of the word "autonomy" complicates the task of analysing it. Dieuaide defines autonomy less in terms of control or prescription than as workers' appropriation of the conception and execution of their own acts. Autonomy cannot - or can no longer - be perceived merely in terms of leeway, but as a set of 'abilities to act'. In contemporary capitalism, workers are called upon to be wholly - body and soul - devoted to their work. Work as a dynamic and cooperative process incorporates the cognitive sphere. Its governance supposes new rules of management founded upon knowledge as an intermediary objective for the workers themselves and not an in se process.

In the same way, based on field research in Brazil and Portugal Cinara Rosenfield argues in "Informational worker autonomy: freedom or control?" that autonomy at work is a composite notion, one which contains both freedom and control. Her meaningful expression of 'conceded autonomy' - autonomia outorgada - contends that in Information and Communication Technologies (ICT), and especially in teleworking (among autonomous and wage-earning teleworkers), conditions do not fundamentally differ from the fordist period. In the current well- 
established information-age, scenarios in Portugal and Brazil are comparable, in spite of the unequal degrees of national development. Rosenfield concludes that deskilled and repetitive work is not the privilege of fordist workers; similarly, work in ICT is not as creative and autonomous as one might assume. In both cases, workers are subordinated, nevertheless information labourers ought to "be at the same time subjects and work in cooperation". As a figure which is imposed, conceded autonomy implies that "the end justifies the means" (Azaïs, 2004). Flexibility, in terms of "time, place, contract, subordination, functional organisation" (Rosenfield), is the guiding principle of telework. Hence she defines it as "an element of the strategic organisational changes that point to new forms of flexible work taken by ICT". The point is not to determine who, between the teleworker and the fordist worker, is the most flexible or autonomous. The answer may be found, beyond the boundaries of economics, within the logic of values and the quest for meaning, given that "conceded autonomy is part of an instrumental logic". Implicitly suggested here is Appay's observation, over a decade ago (1997), which stressed the importance of controlled autonomy in the workplace. The phenomenon does not refer to an individual's particular positioning but refers to the restructurations of labour market organisation, thereby placing the precarisation of work at the core of a more comprehensive social reality (Appay, 2005; Azaiis, 2007). The frontier between the subordinated and the autonomous worker is thus not easy to ascertain and contingent.

In "Subordination or autonomy? The hybridisation of the labour market: the Italian case" Christian Azaïs takes a similar approach when attempting to apprehend the distinction between subordination and autonomy. His concept of hybridisation illustrates how different kinds of contract constructions intertwine with the shifting nature of work relations. The concept is specifically applied here to the Italian case, and to a particular type of labour contract, the co.co.co., collaborazione coordinate e continuativa (coordinated and continuous collaboration). He recalls how the parasubordinazione, as referred to in Italian scholarship, denotes a grey zone between subordination and autonomy. It is telling illustration of hybridisation and of current labour market evolutions. The diversity of contracts in the Italian experience foreshadow modifications of previously assumed European distinctions between 'remunerated life' and 'non remunerated' life' (Bologna, Fumagalli, 1997). As Azaïs underscores, "reality is more complex than the simple separation between dependent and independent work" (Azaïs, 2004). Indeed, the labour market is comprised of multiple configurations of employment status, the most prominent trait being their diversity and the ever-diminishing lack of job security. What makes the wage-earning 
relationship a hybrid one is the establishment of informality as an embedded labour market component.

Now that it has reached the very heart of wage-earning employment, informalisation has transformed it into a hybrid relationship. This is the emblematic link with the South.

Laima Serksnyte-Sappington's, "New organisational realities: individualisation and atomisation in the organisations of 'second modernity" describes how firms have incorporated mutations within their organisational structures. According to Serksnyte, the so-called 'First Modernity' period, during which rationality prevailed, was followed by the "Second Modernity" (Beck, 2000a): the accelerated and flexible techno-scientific development of firms, their ability to appropriate new products and processes, and the shifting human perception towards ever greater task differentiation and training. The changes she points out are not specific to work, but also correspond to overall market adaptations that firms are compelled to undertake. Uncertainty, "dissolving rigid role-based practices and pre-established social and economic expectations" makes the Second Modernity worker "increasingly flexible, fairly autonomous, trainable, multi-tasking, able to cross diverse knowledge sets and embrace risks, while simultaneously coping with change". The author analyses what she terms the new Second Modernity period employee. However, while the "new employee" is called upon to make exceptional efforts, firms apparently remain more reluctant to adapt their own practices. They prefer to autonomise employees, thereby erode their collective responsibility, while maintaining a top-down hierarchical organisation, leaving less freedom to and thus depreciating individual initiatives.

Serksnyte's conclusions are not too far from Cappellin's: both insist upon a certain reluctance of firms to keep up with the times and embrace new behaviours, while in the meantime expecting employees to consistently adapt.

This chapter focuses upon current work and labour market experience and their impact upon individuals. The case studies confirm the thesis of labour market hybridisation, the intricacies of working conditions and contracts with regards to corporate practices that announce major metamorphoses of capitalism.

\section{Autonomy and Capitalism}

The moot question of Autonomy and Capitalism is explored here through a multidisciplinary approach to three contributions, those of a philosopher, of the collaboration among specialists of industrial rela- 
tions, political economy and sociology, and finally of a psychologist. Their contributions each develop various features of globalisation.

In his "Limits of fulfilment in an age of flexibility: changes in Management semantics and the critique of capitalism", Christoph Henning probes the lack of proximity of a number of concepts originating in managerial discourse and which are transposed ipsis litteris in the social sciences. This becomes an obstacle for the researcher, whose scientific method must begin with sufficient distance. Henning is concerned about the proliferation of management concepts in the social sciences and their inability to stimulate critical dynamics for they are in essential contradiction with social theory. The only solution is to return to erstwhile concepts - including "social class", "exploitation", "alienation" - in lieu of importing ill adapted concepts from other fields, whose logical underpinnings can in no way guarantee the "future of a critical theory". As for autonomy, he argues that "instrumentalised autonomy is not autonomy proper". The language of individual autonomy must therefore be reconstructed without sacrificing its scholarly content, as semantic evolutions do not automatically coincide with actual occurrences in the workplace. Language may also reflect shifts in societal self-perceptions or possibly underlying power structures. In order to avoid the pitfall of being disproportionately economics-orientated its perspective it must be essentially political. In this sense, he enlarges in his piece upon Rosenfield's hypothesis on autonomy in favour of a rigorous conceptualisation of globalising labour patterns.

Interested in the changes in work regulation, David Peetz's and Georgina Murray's piece, "Ideology Down Under and the Shifting Sands of Individualism" applies these arguments to transformations in industrial relations. They see the now common wisdom discourse of individualised behaviour as inherently dismissive of the workers collective culture. This elite ideology is subject to overstatement and does not necessarily have equivalents in popular culture or popular ideology.

Taking the example of the Australian capitalist class, they explain how its main representatives - organisers (employer associations and think-tanks), executives and interlocking directorates - are the key architects of this transformative process. These actors create and propagate individualistic ideology amongst elite groups and within the state. The authors contrast this process to shifts of popular opinion with regards to industrial relations and related issues. They conclude that: "the revolution in workplace regulation is an adaptation to the interference of elite, not popular ideology". They convincingly portray a workplace which remains an arena of social dispute, perceived through the light of antagonistic political interests shed by globalisation. 
In the book's last contribution, "Public sectors becoming a flexible labour world: consequences for the employees", Kerstin Wüstner examines the globalised workplace through its consequences upon increasingly flexible structures for public employees. Her findings derive from a survey carried out in a city council in Germany and analysis of private and public sector practices. The specific question is whether job performance of public employees in flexible settings significantly differs from performance of those working in "traditional" public sector environment. Wuestner defines a typology of five prototypical situations which reflect how individuals experience employment: job satisfaction, burnout, distress, autonomy and eustress. Her conclusions on the differences between employees in flexible and "traditional" workplaces shed light upon the pertinent factors and corporate organisational strategies which impact working conditions. The findings can be applied to France and help to understand, for instance, tragic occurrences when whitecollar employees were driven to committing suicide. Their act must not be considered an individual but a collective one. It is a reassertion of group responsibility and refutes the claim of increasing workplace autonomy as a unilateral gain which is cherished by workers.

The political dilemmas induced by a globalising world of work is at the heart of our concerns in this collective endeavour. How are social actors engaged in these ongoing transformations? How do legal frameworks adapt through innovative contractual constructions? How should they be re-interpreted in various contexts? How can one formulate a South to North paradigm, given that analytical categories differ or do not cover identical realities from one country to the next? These problematic threads help weave the articles published here into an emerging research agenda.

Our editorial intent enhances the wealth of social science investigation on the global marketplace and the interdisciplinary debate launched here. Each of the contributions responds to forces for change, be they restructuration, deregulation or innovation, in an age of accelerated pace. They impact economies and societies, whatever their degree of alleged maturity. The contributors confirm our basic hypothesis of politics as the variable which articulates a coherent, if not unified, object of comparison. The theoretical framework has yet to be built.

\section{References}

Appay, B., "Social Précarisation and Controlled Autonomy. Contradictions within the Changing Production Systems", in Work quo vadis? Re-thinking the question of work. Holmer and Karlsson. Aldershot, Brookfield USA, Singapore, Sydney: Ashgate, 1997, pp. 319-330. 
Appay, B., La dictature du succès. Le paradoxe de l'autonomie contrôlée et de la précarisation, Paris, L'Harmattan, Collection Logiques Sociales, 2005.

Assayag, J., La mondialisation vue d'ailleurs - l'Inde désorientée, Paris, Seuil, 2005.

Azaïs, Ch., "Transformations du travail: éléments de comparaison France/ Brésil", Restructurations productives, précarisation, valeurs, $\mathrm{XI}^{\mathrm{e}}$ Journées Internationales de Sociologie du Travail, JIST 2007, Londres, 20-22 juin 2007, www.jist2007.org.

Azaïs, Ch., "De-segmentação do mercado de trabalho e autonomia: algumas palavras introdutórias", Caderno $C R H$, Centro de Recursos Humanos, Universidade Federal da Bahia, Salvador (Brazil), Vol. 17, No. 41, Mai-Ago, 2004, pp. 15-24.

Azaïs, Ch. and Carleial, L., "L'hybridation, caractéristique contemporaine des marchés du travail? Analyse à partir des cas français et brésilien", submitted to Revue Tiers-Monde.

Bayart, J.-F., Le gouvernement du monde - Une critique politique de la globalisation, Paris, Fayard, 2004.

Beck, U., The Brave New World of Work, Cambridge, Polity Press, 2000a.

Beck, U., "What is globalisation?”, Cambridge/Oxford, Polity Press/Blackwell Publishers, 2000b, pp. 99-103.

Berger, S., How we Compete: What Companies around the World are Doing to Make it in Today's Global Economy?, New York, Currency Doubleway, 2006.

Bologna, S. and Fumagalli, A., "Dieci tesi per la definizione di uno statuto del lavoro autonomo", in S. Bologna and A. Fumagalli, Il lavoro autonomo di seconda generazione. Scenari del postfordismo in Italia, Milano, Feltrinelli, 1997, pp. 16-23.

Giraud, O., "A globalização vista do Norte e do Sul: quais seus mecanismos sociais?", Revista do CRH, Globalização e Trabalho, Salvador, No. 51, 2007, pp. 389-399.

Giraud, O., "Nation et globalisation: mécanismes de constitution des espaces politiques pertinents et comparaisons internationales", in J.-C. Barbier and M.-T. Letablier (dir.) Politiques sociales - Enjeux méthodologiques et épistémologiques des comparaisons internationales, Bruxelles, PIE Peter Lang, 2005, pp. 95-115.

Gray, A., Unsocial Europe: Social Protection or Flexploitation?, London, Pluto Press, 2004.

Held, D., McGrew, A. (eds.), The Global Transformations Reader - an Introduction to the Globalisation Debate, Cambridge, Polity Press, 2000.

Held, D., McGrew, A., Goldblatt, D. and Perraton, J., Global transformations Politics, Economics and Culture, Stanford, Stanford University Press Stanford (CA), 1999.

Hirst, P., Thompson, G., Globalisation in question, Cambridge, Polity Press, $2^{\text {nd }}$ ed., 1999. 
"Mathias, G., "État et salarisation restreinte au Brésil", Revue Tiers-Monde, 110, avril-juin, Paris, IEDES/PUF, 1987, pp. 333-346.

Mayntz, R., "New challenges to governance theory", European University Institute, Jean Monnet Chair Paper RSC No. 98/50, 1998.

Ohmae, K., The borderless world, London, Collins, 1990.

Sassen, S., Global networks, Linked cities, London, Routledge, 2002.

Swyngedouw, E., "La transformation des échelles spatiales de la régulation: vers une nouvelle articulation", Géographie, Économie, Société, 2 (2), 2000, p. 211-244.

Therborn, G., "Globalisations: Dimensions, Historical Waves, Regional Effects, Normative Governance", International Sociology, Vol. 15, No. 2, 2000, p. 151-179.

Zeitlin, J. and Pochet, Ph. (eds.), with Magnusson, L., The Open Method of Coordination in Action - the European Employment and Social Inclusion Strategies, Bruxelles, PIE Peter Lang, 2005. 